East African Medical Journal Vol. 86 No. 6 June 2009

PRESENTATION AND MANAGEMENT OF MAXILLOFACIAL TRAUMA IN DAR ES SALAAM, TANZANIA

E. Schaftenaar, MD, Medical Practitioner, G. J. H. Bastiaens, MD, Medical practitioner, Department of Oral and Maxillofacial Surgery, Radboud University Medical Centre, Nijmegen, The Netherlands, E. N. M. Simon, DDS, PhD, Lecturer, Department of Oral and Maxillofacial Surgery, Muhimbili University of Health and Allied Sciences, Dar es Salaam, Tanzania and M. A.W. Merkx, DDS, DMD, PhD, Professor, Department of Oral and Maxillofacial Surgery, Radboud University Medical Centre, Nijmegen, The Netherlands

Request for reprints to: Dr. E. N.M. Simon, Department of Oral Surgery and Oral Pathology, School of Dentistry, Muhimbili University of Health and Allied Sciences, P. O. Box 65014, Dar es Salaam, Tanzania

\title{
PRESENTATION AND MANAGEMENT OF MAXILLOFACIAL TRAUMA IN DAR ES SALAAM, TANZANIA
}

\author{
E. SCHAFTENAAR, G. J. H. BASTIAENS, E. N. M. SIMON and M. A.W. MERKX
}

\begin{abstract}
Objective: To describe the presentation and management of maxillofacial trauma. Design: A retrospective study.

Setting: Department of Oral and Maxillofacial Surgery, Muhimbili National Hospital (MNH), Dar es Salaam, Tanzania.

Subjects: Patients presenting with maxillofacial trauma at the oral and maxillofacial surgery department of the MNH over a six year period (2001-2007).

Method: Information was gathered including age, gender, length of interval between injury and presentation to the hospital, aetiology, pattern of soft tissue injury and fractures, therapy, co-morbidity, complications and number of hospitalisation days. Results: The 21-30-year old age group was most affected. The overall male to female ratio was 4.3:1. The major cause of maxillofacial trauma was road traffic accidents $(42.3 \%)$, followed by assaults $(39.1 \%)$. Over $90 \%$ of the patients sustained soft tissue injuries, with cut wounds seen most frequently $(45.0 \%)$. Of the soft tissue injuries, $75 \%$ required surgical intervention. Most of the fractures were located in the mandible (52.8\%). Accompanying injuries elsewhere in the body occurred in $51.5 \%$. Complications occurred in $13.3 \%$ of the cases. The mean hospitalisation period was 4.3 days. Conclusion: Road traffic accidents and assaults were the most common causes of maxillofacial trauma. Males below forty years of age were the majority of the victims.
\end{abstract}

\section{INTRODUCTION}

Maxillofacial injuries as a part of overall traumatology play an important role in surgical practice (1). Studies concerning the type, treatment and impact of maxillofacial trauma are many (1-11). Only a few of these studies contain meaningful information on soft tissue injuries, which often accompany maxillofacial skeletal trauma $(1,2)$. These soft tissue injuries often result in long-term physical and psychological suffering in patients (7). In developing countries in general and in Tanzania in particular, the number of patients suffering maxillofacial trauma is increasing, possibly due to considerable overcrowding in cities caused by a substantial rural to urban drift, an increase in road traffic volume, poor infrastructure, violence and increasing socio-economic problems $(2,4,8)$. There has been conflicting information, however, on this subject, with some authors citing road traffic accidents as the most common cause $(1,2,6,9)$ and others citing social violence as the most frequent aetiology (3$5,8,10,11)$. In African countries in general and in the main cities such as Dar es Salaam, in particular, an increase of road traffic volume is seen.

Literature on the epidemiology, aetiology and management of maxillofacial trauma in Tanzania is scanty $(4,8)$. The aim of the present study was to audit the level of maxillofacial injuries, manner of treatment, complications and hospitalisation period among patients seen at the MNH in Dar es Salaam, Tanzania.

\section{MATERIALS AND METHODS}

This study was conducted at the Department of Oral and Maxillofacial Surgery, MNH, Dar es 
Salaam, Tanzania. The MNH is the largest of the four referral hospitals in the country and is the only oral and maxillofacial centre in Tanzania. Therefore, all patients with extensive maxillofacial trauma come directly or are referred to this centre by other medical institutions.

This study was conducted from 2001-2007. Data were collected from 532 patient records retrospectively. Information gathered included age, gender, date of presentation, length of interval between injury and presentation in the hospital, aetiology, pattern of soft tissue injury and fractures, manner of treatment, co-morbidity, complications and number of hospitalisation days. The types of "major" if intervention by a maxillofacial surgeon was indicated or were classified as "minor" if intervention by a maxillofacial surgeon was not indicated. Data were analysed by computer using SPSS Inc statistical software version 14.0 (12).

\section{RESULTS}

Records of 532 patients were available for scrutiny. Patients' ages ranged from 1 to 79 years, with a mean of 28.05 years. The highest $(41.5 \%)$ incidence of maxillofacial injuries occurred among the 21-30year-old age group (Figure 1).

Figure 1

Aetiology of maxillofacial trauma according to age

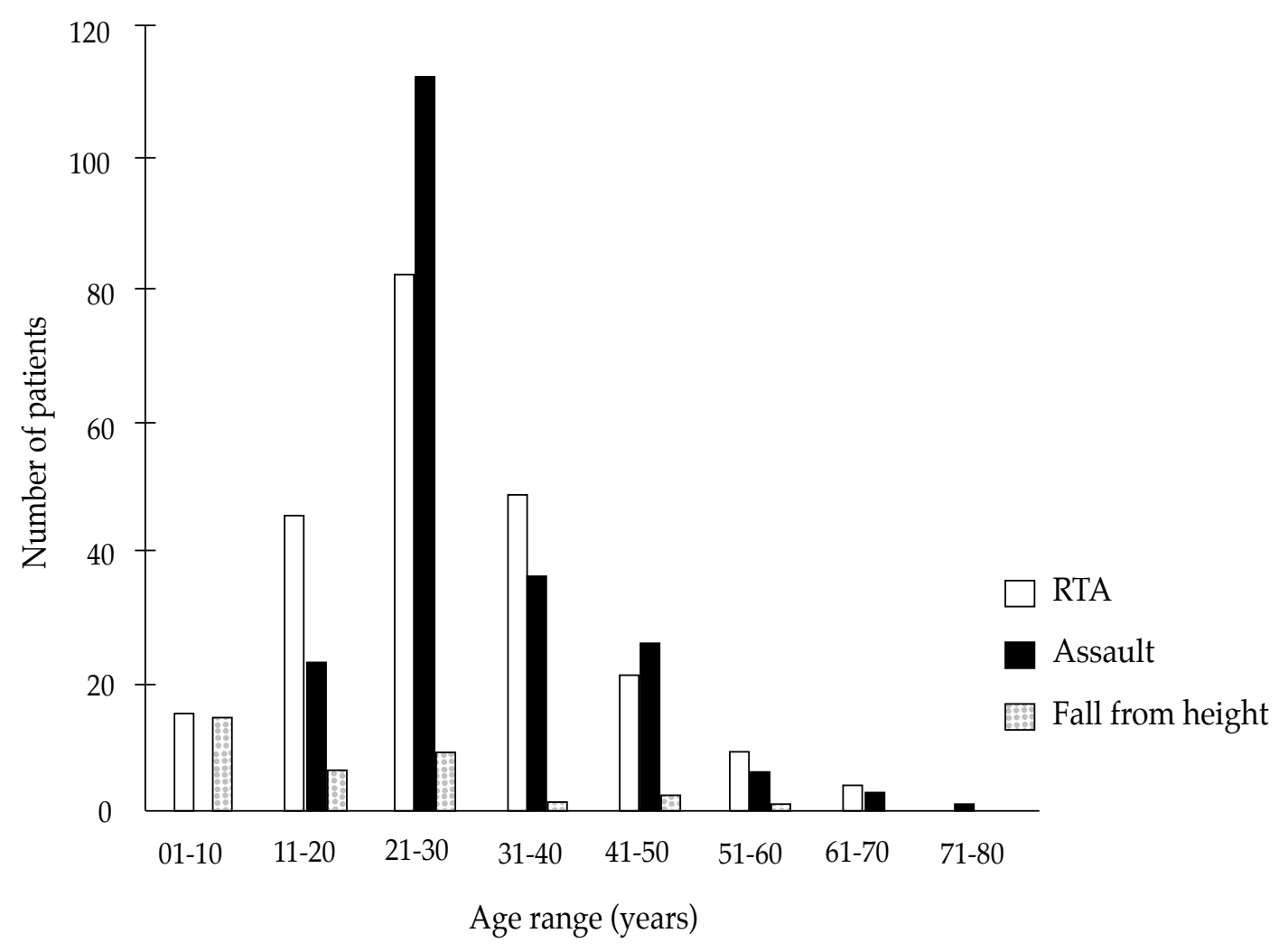

soft tissue injury were categorised into: cut wounds, contusions, lacerations, haematomas, excoriations/ abrasions, penetrating wounds, avulsions and burns. Patients with two or three different types of soft tissue injury were classified as either "two different types of soft tissue injury" or "three different types of soft tissue injury". Soft tissue injuries were classified as
There was an overwhelming male preponderance in all age groups $(81.2 \%)$. A majority $(61.3 \%)$ of the patients presented to the hospital for treatment within 24 hours; 95 (17.9\%) presented to the hospital within 24-48 hours and the remaining $111(20.8 \%)$ patients presented to hospital 48 hours after trauma. Road traffic accidents was the most common aetiological 
factor (42.3\%) followed by assaults (39.1\%) and falls from height $(6.6 \%)$ (Table 1$)$.

The pattern of maxillofacial trauma revealed solitary soft tissue injuries in $188(35.3 \%)$, solitary maxillofacial fractures in $47(8.8 \%)$ and combined soft tissue injuries and maxillofacial fractures in 297 $(55.8 \%)$ patients. Of the $485(92.2 \%)$ patients who sustained soft tissue injuries, single type soft tissue injuries occurred in $383(79.0 \%)$, two different types occurred in $83(17.1 \%)$ and three types occurred in $19(3.9 \%)$ patients. Seventy five per cent of soft tissue injuries were classified as major. The majority $(45.0 \%)$ of all recorded soft tissue injuries were cut wounds (Table 2).

Table 1

Aetiology of maxillofacial trauma according to gender

\begin{tabular}{lllll}
\hline Aetiology & \multicolumn{2}{c}{ Gender } & \multicolumn{2}{c}{ Total } \\
& Male & Female & No. & $(\%)$ \\
\hline Road traffic accident (RTA) & 178 & 47 & 225 & 42.3 \\
Assault & 176 & 32 & 208 & 39.1 \\
Fall from height & 23 & 12 & 35 & 6.6 \\
Sports/game & 23 & 3 & 26 & 4.9 \\
Work & 19 & 2 & 21 & 3.9 \\
Gunshot & 7 & 1 & 8 & 1.5 \\
Other & 6 & 3 & 9 & 1.7 \\
\hline Total & 432 & 100 & 532 & 100 \\
\hline
\end{tabular}

Table 2

Pattern of soft tissue injuries

\begin{tabular}{lcr}
\hline Type(s) & No. of patients & $(\%)$ \\
\hline Single & 383 & 79 \\
Two & 83 & 17.1 \\
Three & 19 & 3.9 \\
\hline Total & 485 & 100 \\
\hline Type & & \\
$\quad$ Minor & 119 & 24.5 \\
Major & 366 & 75.5 \\
\hline Total & 485 & 100 \\
\hline Type & & \\
Cut wound & 273 & 45 \\
Contusion & 139 & 22.9 \\
Laceration & 107 & 17.7 \\
Haematoma & 37 & 6.1 \\
Excoriation/abrasion & 26 & 4.3 \\
Puncture wound & 16 & 2.6 \\
Avulsion & 6 & 1.0 \\
Burns & 2 & 0.3 \\
\hline Total & 606 & 100 \\
\hline
\end{tabular}

Three hundred and thirty four $(64.7 \%)$ patients sustained different types of fracture. Solitary fractures occurred in $298(86.6 \%)$, two fractures in 36 $(10.5 \%)$ and three fractures in $10(2.9 \%)$ patients. The fracture site distribution showed that $52.8 \%$ occurred in the mandible, $20.8 \%$ involved the alveolar bone, $11.5 \%$ the maxilla, $8.8 \%$ the zygomatic complex, $5.8 \%$ the nasal bones and $0.5 \%$ in the frontobasal bone. In the mandible the most frequently involved part was the body $(50.6 \%)$. The most common maxillary fracture was the Le Fort II level in 25 (54.3\%), followed by Le Fort I in $12(26.1 \%)$ and Le Fort III in $9(19.6 \%)$ patients.

The treatment of soft tissue injuries depended on the type of injury. The most common forms of treatment were wound dressing, surgical toilet and stitching. Mandibular fractures were mostly managed by closed reduction and fixation (185 fractures), 155 (83.8\%) of which involved maxillomandibular fixation (MMF). Open reduction and fixation was only performed in $12.3 \%$ of the mandibular fractures, $6.0 \%$ of the alveolar bone fractures, $39.1 \%$ of the maxillary fractures, $48.6 \%$ of the zygomatic complex fractures and $17.4 \%$ of the nasal bone (Table 3). 
Table 3

Treatment of maxillofacial fractures

\begin{tabular}{|c|c|c|}
\hline Treatment & No. of fractures & $(\%)$ \\
\hline Mandibular & 211 & \\
\hline Closed MMF & 155 & 73.5 \\
\hline Closed non-MMF & 30 & 14.2 \\
\hline Open MMF & 5 & 2.3 \\
\hline Open non-MMF & 21 & 10 \\
\hline Alveolar & 83 & \\
\hline Closed & 78 & 94 \\
\hline Open & 5 & 6 \\
\hline Maxilla & 46 & \\
\hline Closed MMF & 18 & 39.2 \\
\hline Closed non-MMF & 10 & 21.7 \\
\hline Open MMF & 4 & 8.7 \\
\hline Open non-MMF & 14 & 30.4 \\
\hline Zygomatic complex & 35 & \\
\hline Closed & 18 & 51.4 \\
\hline Open & 17 & 48.6 \\
\hline Nasal bone & 23 & \\
\hline Closed & 19 & 82.6 \\
\hline Open & 4 & 17.4 \\
\hline Frontobasal & 2 & \\
\hline Closed & 2 & 100 \\
\hline Open & 0 & 0 \\
\hline
\end{tabular}

Table 4

Associated complications in patients with maxillofacial trauma

\begin{tabular}{lll}
\hline Complication & No. & $(\%)$ \\
\hline Neurological & 21 & 29.6 \\
Post-operative infection & 20 & 28.2 \\
Malocclusion & 18 & 25.4 \\
Pre-operative infection & 7 & 9.9 \\
Non-union & 5 & 7 \\
\hline Total & 71 & 100 \\
\hline
\end{tabular}

Patients were followed up for periods of up to six weeks after treatment. Associated complications occurred in $71(13.3 \%)$ patients. The most common complication was neurological deficit (29.6\%), followed by postoperative infections in 20 patients and malocclusion in 18 patients (Table 4). One third $(34.0 \%)$ of the patients attended the hospital for a single day while $451(84.8 \%)$ of the admitted patients were discharged within one week and; the mean hospitalisation period was 4.3 days.

\section{DISCUSSION}

Most patients who suffer maxillofacial trauma in Dar es Salaam and the surrounding regions either first reported to the municipal hospitals and health centres before they were referred to the $\mathrm{MNH}$ or depending on the urgency they would come directly. There were a few who would report to private health institutions and a minority who, for different reasons might have failed to report to any health facility at all. This means that our data might have missed those who did not turn up at MNH. However, to a large extent the data are representative since the majority would ultimately seek treatment at MNH. Maxillofacial trauma is accompanied by a high social and financial impact, leading toburdens that counteract the aim of economic growth and stability pursued by many developing countries. The present study was done in order to chart out proper management and to assess future planning strategies by verification of the aetiology of maxillofacial trauma. Asubstantial number of injuries that had previously been attributed to "falls" in fact turned out to have been caused by RTA. For example, a fall from a bicycle was often considered a "fall", although in the present study this was considered to have been RTA. This can be an explanation for the fact that Deogratiuset al. reported "falls" as the second and RTA as the third causes of trauma respectively (4). If soft tissue injuries are excluded from our results and only maxillofacial fractures are analysed, in the present study RTA still remains the major cause followed by assault. Our figures are consistent with the results from most African studies that similarly reported RTA as the most common cause $(1,2,6,13)$. They are, however, in contrast with the findings of similar reports from Kenya, Zimbabwe and Northern Nigeria, in which assault was found to have been the major cause of maxillofacial injury $(10,14,15)$.

In the present study, the male to female ratio was 4.3:1 confirming the findings of other studies $(2,4,8,14,16-18)$. In Tanzania, like in many other societies, males are exposed to dangerous occupations like driving more often than females. This explains the high male to female ratio seen in this study. Also, in agreement with previous studies, the most affected age group was the 21-30-year-old s(1, 4-6,8,13,16-18). Rural to urban migration has led to a high number of unemployed people and those without a stablemeans of income in cities like Dar es Salaam. Such situations usually lead to a high level of social unrest and often result in interpersonal altercations. Furthermore, the consumption of excessive amounts of alcohol, indulgence in use of narcotics and sports activities could be other explanations for the large number of patients belonging to these two groups.

Soft tissue injury was classified as major if treatment by a surgeon was indicated. Since 75.5\% of soft tissue injuries were major, this was a clear indication that maxillofacial traumatology, apart 
from fractures, should also include maxillofacial soft tissue injuries.

This is supported by the fact that soft tissue injuries in the facial region require more care than wound elsewhere in the body because of the desired aesthetic results. Despite the fact that there are many advantages of open reduction and internal rigid fixation (19), this may notbe the most common method of treatment in developing countries $(4,9,18,20)$. The relatively high costs, a lack of theatre capacity, trained surgeons, materials for osteosynthesis and the desired instruments to perform this type of treatment have resulted in closed reduction predominating (20). The closed reduction and fixation method is simple and cheap to apply, but has some disadvantages, such as prolonged maxillomandibular fixation resulting in poor oral hygiene and inadequate nutrition. In the presentstudy, $51.5 \%$ of the patients suffered associated injuries including neurological deficits, headaches, dizziness, contusions and concussions. Orthopaedic injuries included fractures of the limbs and different types of joint problems. In agreement with international studies (22), the mean hospitalisation period in the present study was 4.3 days, indicating effective maxillofacial trauma management.

In conclusion RTA and assault were the major causes of maxillofacial trauma. The majority of patients whosuffered maxillofacial trauma weremales below the ageoffortyyears. Werecommend that sinceotherstudies have shown that the incidence of maxillofacial trauma tended to decrease when traffic rules and regulations were tightened and the infrastructure was improved (23), such measures should be introduced in Dar es Salaam. These should include the mandatory use of seatbelts and crash helmets.Also, community education to the urban population on proper road use and safety measures would complement the other measures in the further reduction of maxillofacial injuries.

\section{ACKNOWLEDGEMENTS}

To the Muhimbili National Hospital administration for giving permission for the study to take place and to be published. The cooperation of staff at the DentalSchool's Department of OralSurgery and Oral Pathology and nurses working in wards 19 and 20 where the majority of the patients were admitted is highly appreciated.

\section{REFERENCES}

1. Oji, C. Jaw fractures in Enugu, Nigeria, 1985-1995. Br. J. Oral Maxillofac. Surg. 1999; 37:106-109.

2. Adebayo, E.T., Ajike, O.S. and Adekeye, E.O. Analysis of the pattern of maxillofacial fractures in Kaduna, Nigeria. Br. J. Oral. Maxillofac. Surg. 2003;41: 396-400.

3. Boole, J.R., Holtel, M., Amoroso, P. and Yore, M. 5196 mandibular fractures among 4381 active duty army soldiers, 1980 to 1998. Laryngoscope 2001;11:1691-1696.

4. Deogratius, B.K., Isaac, M.M. and Farrid, S. Epidemiology and management of maxillofacial fractures treated at Muhimbili National Hospital in Dar es Salaam, Tanzania, 1998-2003. Int. Dent. J. 2006; 56: 131-134.

5. Dimitroulis, G. and Eyre, J. A 7-year review of maxillofacial trauma in a central London hospital. Br. Dent. J. 1991; 170: 300-302.

6. Fasola, A.O., Nyako, E.A.,Obiechina, A.E. and Arotiba, J.T. Trends in the Characteristics of Maxillofacial Fractures in Nigeria. J. Oral Maxillofac. Surg. 2003; 61: 1140-1143.

7. Iida, S., Kogo, M., Sugiura, T. et al. Retrospective analysis of 1502 patients with facial fractures. Int. J. Oral Maxillofac. Surg. 2001; 30: 286-290.

8. Moshy, J., Mosha, H.J. and Lema, P.A. Prevalence of maxillo-mandibular fractures in mainland Tanzania. East Afr. Med. J. 1996;.73:172-175.

9. Motamedi, M.H.K. An Assessment of maxillofacial fractures: A 5-Year Study of 237 Patients. J. Oral Maxillofac. Surg. 2003; 61:61-64.

10. Mwaniki, D.L. and Guthua, S.W. Occurrence and characteristics of mandibular fractures in Nairobi, Kenya. Br. J. Oral Maxillofac. Surg. 1990; 28:200-202.

11. Schon R, Roveda SI, Carter B. Mandubular fractures in Townsville, Australia: incidence, aetiology and treatment using the 2.AO/ASIF mini-plate system. Br. J. Oral Maxillofac. Surg. 2001;39:145-148.

12. SPSS Inc version 14.0. The statistical Package for the Social Sciences. Chicago, IL: SPSS Inc, 2005.

13. Adeyemo, W.L., Ladeinde, A.L., Ogunlewe, M.O. and James, $\mathrm{O}$. Trends and characteristics of oral and maxillofacial injuries in Nigeria: a review of the literature. Head and face medicine 2005;1:7

14. Khan, A.A. A retrospective study of injuries to the maxillofacial skeleton in Harare, Zimbabwe. Br. J. Oral Maxillofac. Surg. 1988; 26:435-439.

15. Olasoji, H.O., Tahir, A. and Arotiba, G.T. Changing picture of facial fractures in northern Nigeria. Br. J. Oral Maxillofac. Surg. 2002; 40:140-143.

16. Abiose, B.O. Maxillofacial skeleton injuries in the Western states of Nigeria. Br. J. Oral Maxillofac. Surg. 1986; 24: 31-39.

17. Allan, B.P. and Daly, C.G. Fractures of the mandible, a 35 year retrospective study. Int. J. Oral Maxillofac. Surg. 1990; 19: 268-271.

18. Ugboko, V.I., Odusanya, S.A. and Fagade, O.O. Maxillofacial fractures in a semi-urban Nigerian teaching hospital. A review of 442 cases. Int. J. Oral Maxillofac. Surg. 1998; 27: 286-289.

19. Schwimmer, A.M. and Greenberg, A.M. Management of mandibular trauma with rigid internal fixation. Oral Surg. 1986; 62:630-637.

20. Nair, K.B. and Paul, G. Incidence and aetiology of fractures of the facio-maxillary skeleton in Trivandrum: a retrospective study. Br. J. Oral Maxillofac. Surg. 1986; 24: 40-43.

21. Schmidt, B.L., Kearns, G., Gordon, N. and Kaban L.B. A Financial Analysis of Maxillomandibular Fixation Versus Rigid Internal Fixation for Treatment of Mandibular Fractures. J. Oral Maxillofac. Surg. 2000; 58:1206-1210.

22. Beek, G.J.van and Merkx, C.A. Changes in the pattern of fractures of the maxillofacial skeleton. Int. J. Oral Maxillofac. Surg. 1999; 28:424-428.

23. Roccia, F., Diaspro, A., Nasi, A., Berrone, S. Management of sport-related maxillofacial injuries. J. Craniofac. Surg. 2008;19:377-382. 